\title{
Definiëring van de patiëntenpopulatie: een probleem bij het onderzoek naar palliatieve zorg
}

Sander Borgsteede, Luc Deliens, Anneke Francke, Wim Stalman, Dick Willems, Jacques van Eijk, Gerrit van der Wal

\section{Inleiding}

In 1990 definieerde de World Health Organization (WHO) palliatieve zorg als volgt:

Palliatieve zorg is de actieve, totale zorg voor patiënten op het moment dat hun ziekte niet meer te genezen is. Pijnbeheersing, en de bestrijding van andere lichamelijke klachten, is net zo belangrijk als de aandacht voor psychologische, sociale en spirituele problemen. Het algemene doel van palliatieve zorg is het bereiken van de hoogst mogelijke kwaliteit van leven, voor zowel de patiënt als diens naasten. ${ }^{1}$

Het is nu een algemeen aanvaarde gedachte dat zorgverleners bij iedere chronische ziekte al in een vroeg stadium aandacht moeten hebben voor palliatieve zorg. Daarom heeft de WHO in 2002 de definitie aangepast:

\section{Samenvatting}

Borgsteede SD, Deliens L, Francke AL, Stalman WAB, Willems DL, Van Eijk JThM, Van der Wal G. Definiëring van de patiëntenpopulatie: een probleem bij het onderzoek naar palliatieve zorg. Huisarts Wet 2008;51(2):85-9.

Inleiding In het onderzoek naar palliatieve zorg ontbreekt een duidelijke definitie van patiëntenpopulaties en zijn er geen criteria voor een indeling in groepen. De effecten van de gekozen inclusiecriteria zijn daardoor niet bekend. Ons onderzoek is een eerste stap om deze lacune op te vullen. Wij onderzochten hoe de toepassing van drie criteria voor groepsindeling uitwerkte in verschillende populaties die waren onderzocht op basis van grootte, aantal dokter-patiëntcontacten en demografische gegevens.

Methoden Huisartsen ontvingen een vragenlijst voor alle patiënten die overleden tijdens de Tweede Nationale Studie naar ziekten en verrichtingen in de huisartspraktijk $(n=2194)$. De vragen waren: 1) kregen de patiënten een non-curatieve behandeling?

2) kregen de patiënten palliatieve zorg? en 3) verwachtte de arts het overlijden?

Resultaten De respons was $73 \%$. Het criterium 'overlijden werd verwacht' was van toepassing op de meeste patiënten (62\%), gevolgd door 'palliatieve zorg' (46\%) en 'non-curatieve behandeling' (39\%). De overeenkomst tussen de populaties op basis van deze definities was redelijk tot matig. Kankerpatiënten vielen
Palliatieve zorg is een benadering die de kwaliteit van het leven verbetert van patiënten en hun naasten die te maken hebben met een levensbedreigende aandoening, door het voorkomen en verlichten van lijden, door middel van vroegtijdige signalering en zorgvuldige beoordeling en behandeling van pijn en andere problemen van lichamelijke, psychosociale en spirituele aard. ${ }^{1,2}$

Beide definities omschrijven de doelstellingen van palliatieve zorg, maar zijn nogal vaag over de betrokken populatie. Terwijl de doelstellingen betrekking hebben op de symptomen en problemen van de patiënten, wordt de populatie bepaald door de ziekte van de patiënt: ziekten die niet reageren op een curatieve behandeling (1990), of ziekten die levensbedreigend zijn (2002). Het is dan ook niet verwonderlijk dat politici en onderzoekers popula-

vaker onder de criteria 'palliatieve zorg' en 'overlijden werd verwacht', dan onder 'niet-curatieve behandeling'.

Discussie Dit onderzoek laat aanzienlijke verschillen tussen populaties zien, afhankelijk van de inclusiecriteria die bij de selectie zijn toegepast. Verder onderzoek naar palliatieve zorg moet rekening houden met beperkingen door bepaalde inclusiecriteria en mogelijke afwijkingen die daardoor ontstaan.

VU medisch centrum, EMGO Instituut, Afdeling Sociale Geneeskunde, Van der Boechorststraat 7, 1081 BT Amsterdam: dr. S.D. Borgsteede; prof.dr. L. Deliens (ook werkzaam bij Vrije Universiteit Brussel, Faculteit Geneeskunde en Farmacie, Onderzoeksgroep Zorg rond het Levenseinde); prof. dr. G. van der Wal. NIVEL: dr. A.L. Francke. VU medisch centrum, EMGO Instituut, Afdeling Huisartsgeneeskunde: prof.dr. W.A.B. Stalman. AMC, Afdeling Huisartsgeneeskunde: prof.dr. D.L. Willems. Universiteit Maastricht, sectie Medische Sociologie, Capaciteitsgroep Zorgwetenschappen: prof.dr. J.Th.M. van Eijk.

Correspondentie: s.borgsteede@vumc.nl.

Mogelijke belangenverstrengeling: niets aangegeven

Dit artikel is een bewerkte vertaling van: Borgsteede SD, Deliens L, Francke AL, Stalman WAB, Willems DL, Van Eijk JThM, Van der Wal G. Defining the patient population: one of the problems for palliative care research. Palliative Medicine 2006;20:63-8. Publicatie gebeurt met toestemming van de uitgever. 
ties palliatievezorgpatiënten op verschillende manieren definiëren. Het ontbreken van een algemeen geaccepteerde definiëring van populaties is een van de grootste problemen voor een verdere ontwikkeling van de palliatieve zorg. ${ }^{4-6}$ Duidelijke populatiecriteria zijn noodzakelijk om de resultaten van onderzoeken uit diverse landen te kunnen vergelijken. 5,6

Bij onderzoek in een algemene populatie is nog onbekend welk effect de gekozen inclusiecriteria hebben op de uitkomsten en kenmerken van de populatie. Met ons onderzoek wilden we ontdekken en beschrijven welke consequenties de toepassing van verschillende inclusiecriteria heeft op een geselecteerde populatie. Wij gebruikten drie criteria:

1. Behandeling is niet gericht op genezing en ook niet op levensverlenging. Dit criterium is direct overgenomen van de WHO-definitie van palliatieve zorg. ${ }^{1}$

2. De behandelend arts oordeelt dat de patiënt palliatieve zorg ontving. We kozen dit criterium omdat het de meest gangbare opvatting is. Deze subjectieve beoordeling geeft de beoordelaar vrijheid om diverse factoren die betrekking hebben op palliatieve zorg in overweging te nemen.

3. De dood van de patiënt was niet plotseling en niet onverwacht. Hiermee selecteerden we patiënten die al een risico liepen om te overlijden op het moment dat ze palliatieve zorg kregen. We zien dit criterium terug in verschillende Nederlandse en Europese onderzoeken naar het levenseinde. .,8 $^{-1}$

Onze centrale onderzoeksvraag was: welke overeenkomsten en verschillen in populatie-omvang, aantal arts-patiëntcontacten en demografische kenmerken zijn er tussen populaties die geselecteerd zijn op basis van de drie genoemde criteria?

\section{Methoden}

\section{Verzameling van onderzoeksgegevens}

In dit onderzoek gebruikten we gegevens uit de Tweede Nationale Studie naar ziekten en verrichtingen in de huisartspraktijk (Tweede Nationale Studie, NS2). Hieraan deed een representatieve steekproef van 96 Nederlandse huisartsenpraktijken mee, met in totaal 375.899 patiënten. De één jaar durende registraties in de praktijken begonnen tussen april 2000 en januari 2001. ${ }^{9}$ De deelnemers registreerden 1,6 miljoen contacten met patiënten digitaal. ${ }^{10}$

\section{Criteria voor palliatieve zorg}

Voor dit onderzoek stelden we een aanvullende enquête op waarmee we de patiënten die overleden tijdens NS2 konden indelen op basis van drie vragen die hun huisarts beantwoordde:

1. Ontving deze patiënt een behandeling die gericht was op genezing of op levensverlenging?

2. Gaf $\mathrm{u}$ of een collega palliatieve zorg?

3. Was het overlijden van de patiënt plotseling en geheel onverwacht?

Wij hebben deze drie vragen omgezet in criteria, zodat de tekst gemakkelijker te interpreteren was. Een 'ja' voor een criterium betekende dat een patiënt voor dat criterium palliatieve zorg ontving. We vertaalden de vragen als volgt. Bij een 'nee' op vraag 1 deelden we de patiënt in als positief op criterium 1: niet-curatieve behandeling. Een positief antwoord op vraag 2 betekende een positieve indeling bij criterium 2: palliatieve zorg. En een 'nee' op vraag 3 leidde tot een positieve indeling bij criterium 3: overlijden werd verwacht. De figuur toont de criteria en geeft aan welke acht combinaties mogelijk zijn. De achtste combinatie vertegenwoordigt patiënten voor wie de huisartsen alle criteria als negatief beoordeelden.

Alle patiënten overleden tijdens de Nationale Studie, waardoor de gegevens betrekking hadden op variabele perioden. Om de contacten tussen huisarts en patiënt te kunnen analyseren, definieerden we een populatie patiënten die op zijn vroegst drie maanden na aanvang van de Nationale Studie waren overleden. De analyse van het aantal contactmomenten tussen huisarts en patiënt hebben wij beperkt tot de periode van drie maanden vóór het overlijden.

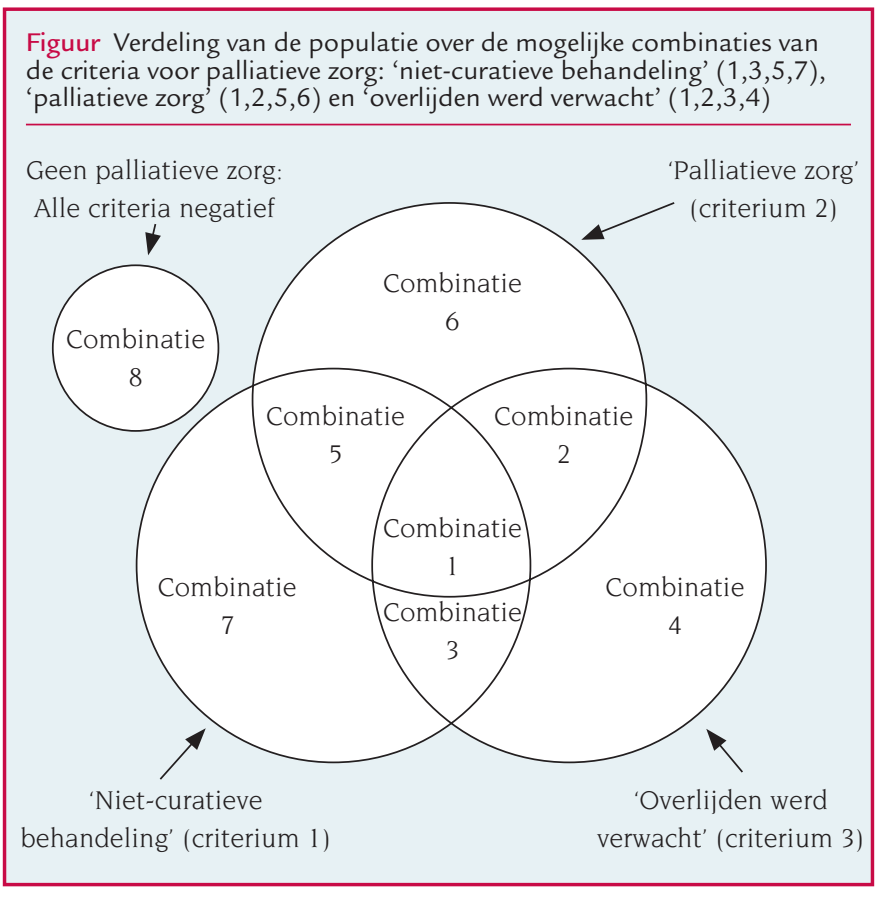

\section{Analyse}

De verschillen in omvang van de onderzochte populaties stelden we vast met frequentietabellen. Om de vraag naar overeenkomsten te beantwoorden, vergeleken we de frequenties van de variabelen 'sekse', 'leeftijd' en 'onderliggende aandoeningen' tussen de populaties met frequentietabellen en kappa's ( $\kappa)$ als maat voor overeenkomst. Een waarde kleiner dan 0,2 betekent een slechte overeenstemming; 0,21-0,40 matig; 0,41-0,60 redelijk; 0,61-0,80 goed en groter dan 0,80 betekent een zeer goede overeenstemming. ${ }^{11}$ We maakten deze vergelijking voor de variabelen 'sekse' en 'onderliggende aandoeningen', waarbij we alle gegevens gebruikten. Voor de vergelijking van het aantal huisarts-patiëntcontacten in de laatste drie maanden van het leven 
waren minder gegevens beschikbaar omdat sommige patiënten overleden binnen de eerste drie maanden van het onderzoek. Met de $\chi^{2}$-toets bepaalden we of de verschillen statistisch significant waren $(\alpha=5 \%)$. In deze analyse gebruikten we de variabelen die we ook voor de overeenkomst hadden toegepast.

\section{Resultaten}

\section{Populatieomvang}

Gedurende het onderzoeksjaar overleden 2194 van de 375.899 patiënten in de 96 huisartsenpraktijken (0,6\%). Van de 2194 verzonden vragenlijsten werden er 1771 teruggestuurd (81\%). Hiervan waren er 1608 volledig ingevuld en bruikbaar voor het onderzoek (73\% bruikbare respons).

De meeste patiënten (69\%) werden ingedeeld bij ten minste één criterium voor palliatieve zorg en 26\% bij alle drie (tabel 1). Bij 62\% van de patiënten kwam het overlijden niet onverwacht, $46 \%$ kreeg palliatieve zorg en 39\% een niet-curatieve behandeling. Voor 31\% van de patiënten was geen van de drie criteria van toepassing

\section{Kenmerken en overeenkomsten van de onderzochte populaties}

De drie populaties die op basis van de criteria waren ingedeeld verschilden niet wat betreft gemiddelde leeftijd en sekseverhou- dingen (tabel 2 en 3). We vonden een matige overeenkomst tussen de populatie 'niet-curatieve behandeling' en 'palliatieve zorg' $(\kappa=$ $0,36)$. Hetzelfde gold voor de overeenkomst met 'overlijden werd verwacht' $(\kappa=0,39)$. Tussen 'palliatieve zorg' en 'overlijden werd verwacht' was de overeenkomst redelijk ( $\kappa=0,57)$.

In de 'niet-curatieve behandeling'-populatie kwamen relatief minder kankerpatiënten voor en meer patiënten met andere aandoeningen dan in de andere populaties. In de 'palliatieve zorg'populatie waren relatief meer kankerpatiënten dan in de populatie 'overlijden werd verwacht'. In de populatie 'palliatieve zorg' hadden meer patiënten minstens één huisarts-patiëntcontact in de laatste drie levensmaanden (95\%) vergeleken met de populaties 'niet-curatieve behandeling' en 'overlijden werd verwacht' (90\%). De overeenkomst tussen de drie populaties gezamenlijk was matig tot redelijk.

\section{Discussie}

In dit onderzoek deelden we één onderzoeksgroep op drie manieren in op grond van drie criteria voor palliatieve zorg: 'niet-curatieve behandeling', 'palliatieve zorg' en 'overlijden werd verwacht'. Hiermee konden we overeenkomsten en verschillen tussen de betrokken subpopulaties onderzoeken. Het criterium 'overlijden werd verwacht' was van toepassing op de meeste patiënten (62\%), gevolgd door 'palliatieve zorg' (46\%) en 'niet-curatieve behandeling' (39\%). De overeenkomst tussen deze drie populaties was matig tot redelijk. Kankerpatiënten vielen vaker onder de criteria 'palliatieve zorg' en 'overlijden werd verwacht', dan onder 'niet-curatieve behandeling'. De 'palliatieve zorg'-populatie had meer huisartspatiëntcontacten.

In ander gepubliceerd onderzoek is het gemiddelde percentage van de respons $61 \%$. Onze respons van $73 \%$ is daarmee vergeleken hoog, zeker als we in aanmerking nemen dat de schriftelijke respons op een aanvullende enquête in de regel laag is.

*In de enquête vroegen wij: 'Ontving deze patiënt een behandeling die gericht was op genezing of op levensverlenging?' Criterium 1 was positief als de huisarts antwoordde 'nee, de behandeling was niet gericht op genezing en ook niet op levensverlenging'.

†In de enquête vroegen wij: 'Gaf u of een collega palliatieve zorg?' Criterium 2 was positief als de huisarts 'ja' antwoordde.

‡In de enquête vroegen wij: 'Was het overlijden van de patiënt plotseling en geheel onverwacht?’ Criterium 3 was positief als de huisarts 'nee' antwoordde.

Tabel 2 Demografische kenmerken en onderliggende aandoeningen in de totale populatie en overeenkomsten $\left(\kappa^{*}\right)$ in variabelen tussen populaties ingedeeld volgens de drie criteria: 'niet-curatieve behandeling' (NCB), 'palliatieve zorg' (PZ), en 'overlijden werd verwacht' (OV) ( $n=1608)$

\begin{tabular}{|c|c|c|c|c|c|c|c|c|c|c|c|c|}
\hline \multirow[b]{3}{*}{ Demografische kenmerken } & \multicolumn{3}{|c|}{$\begin{array}{c}\text { Criterium 1: } \\
\text { NCB }\end{array}$} & \multicolumn{3}{|c|}{$\begin{array}{c}\text { Criterium 2: } \\
\text { PZ }\end{array}$} & \multicolumn{3}{|c|}{$\begin{array}{c}\text { Criterium 3: } \\
\text { OV }\end{array}$} & \multirow{2}{*}{$\begin{array}{c}1 \text { versus } 2 \\
\kappa\end{array}$} & \multirow{2}{*}{$\begin{array}{c}1 \text { versus } 3 \\
\kappa\end{array}$} & \multirow{2}{*}{$\begin{array}{c}2 \text { versus } 3 \\
\kappa\end{array}$} \\
\hline & $\%$ & $95 \%-B I$ & SD & $\%$ & $95 \%-B I$ & SD & $\%$ & $95 \%-B \mid$ & SD & & & \\
\hline & 45 & $40-49$ & & 47 & $43-51$ & & 48 & $44-51$ & & 0,36 & 0,39 & 0,57 \\
\hline - gemiddelde leeftijd & 79 & & 13 & 75 & & 15 & 76 & & 14 & & & \\
\hline \multicolumn{13}{|l|}{ Aanwezige ziektes } \\
\hline - kanker & 44 & $39-48$ & & 55 & $52-60$ & & 48 & $45-52$ & & 0,12 & 0,12 & 0,36 \\
\hline - hartfalen & 16 & $13-20$ & & 16 & 14-19 & & 17 & $15-20$ & & 0,42 & 0,44 & 0,49 \\
\hline - COPD & 6,2 & $4,5-8,4$ & & 6,9 & $5,1-8,9$ & & 7,5 & $5,9-9,3$ & & 0,16 & 0,33 & 0,19 \\
\hline - andere ziekten & 41 & $37-45$ & & 27 & $24-31$ & & 34 & $31-37$ & & 0,39 & 0,45 & 0,45 \\
\hline Totaal & 628 & & & 743 & & & 991 & & & 0,36 & 0,39 & 0,54 \\
\hline
\end{tabular}


Tabel 3 Aantal contacten in de populatie in de periode van drie maanden voor overlijden en overeenkomsten $\left(\kappa^{*}\right)$ in variabelen tussen populaties ingedeeld volgens de drie criteria: 'niet-curatieve behandeling' (NCB), 'palliatieve zorg' (PZ), en 'overlijden werd verwacht'(OV) $\left(n=1122^{\dagger}\right)$

\begin{tabular}{|c|c|c|c|c|c|c|c|c|c|c|c|c|}
\hline \multirow[b]{3}{*}{$\begin{array}{l}\text { Huisarts-patiëntcontacten } \\
\text { - ten minste één contact } \\
\text { - gemiddeld aantal contacten }\end{array}$} & \multicolumn{3}{|c|}{$\begin{array}{l}\text { Criterium 1: } \\
\text { NCB }\end{array}$} & \multicolumn{3}{|c|}{$\begin{array}{c}\text { Criterium 2: } \\
\text { PZ }\end{array}$} & \multicolumn{3}{|c|}{$\begin{array}{c}\text { Criterium 3: } \\
\text { OV }\end{array}$} & \multirow{2}{*}{$\begin{array}{c}1 \text { versus } 2 \\
\kappa\end{array}$} & \multirow{2}{*}{$\begin{array}{c}1 \text { versus } 3 \\
\kappa\end{array}$} & \multirow{2}{*}{$\begin{array}{c}2 \text { versus } 3 \\
\kappa\end{array}$} \\
\hline & $\%$ & 95\%-BI & SD & $\%$ & 95\%-BI & SD & $\%$ & 95\%-BI & SD & & & \\
\hline & $\begin{array}{l}90 \\
11,2\end{array}$ & $87-93$ & 8,0 & $\begin{array}{l}95 \\
12,4\end{array}$ & 93-98 & 8,2 & $\begin{array}{l}90 \\
10,9\end{array}$ & $87-92$ & 8,1 & 0,37 & 0,37 & 0,55 \\
\hline Totaal & 448 & & & 520 & & & 697 & & & & & \\
\hline
\end{tabular}

${ }^{*} \kappa<0,2$ betekent slechte overeenkomst, 0,21-0,40 matige overeenkomst, 0,41-0,60 redelijke overeenkomst, 0,61-0,80 goede overeenkomst en $>0,80$ zeer goede overeenkomst.

$\dagger$ Alleen patiënten die ten minste drie maanden na aanvang van het onderzoek overleden.

Ons onderzoek heeft echter ook beperkingen. De NS2 was niet specifiek ontworpen voor onderzoek naar palliatieve zorg. Er waren daarom geen gegevens beschikbaar over enkele zaken die relevant waren voor palliatieve zorg.

De resultaten van ons onderzoek geven duidelijkheid over de populaties patiënten in het onderzoek naar palliatieve zorg. De verdeling van alle onderzochte patiënten toont aan dat er weinig overeenkomst is tussen patiënten van wie het levenseinde verwacht wordt. Dit illustreert de moeilijkheid om patiënten die palliatieve zorg krijgen in onderzoek te benoemen. We vonden ook overlap tussen de populaties. Een mogelijke verklaring daarvoor is dat de drie criteria weliswaar aan elkaar gerelateerd zijn, maar ook verschillen. 'Niet-curatieve behandeling' kan gaan over de intentie om palliatieve zorg te verlenen. 'Palliatieve zorg' kan de mening van de huisarts weergeven: hij vond dat hij daadwerkelijk

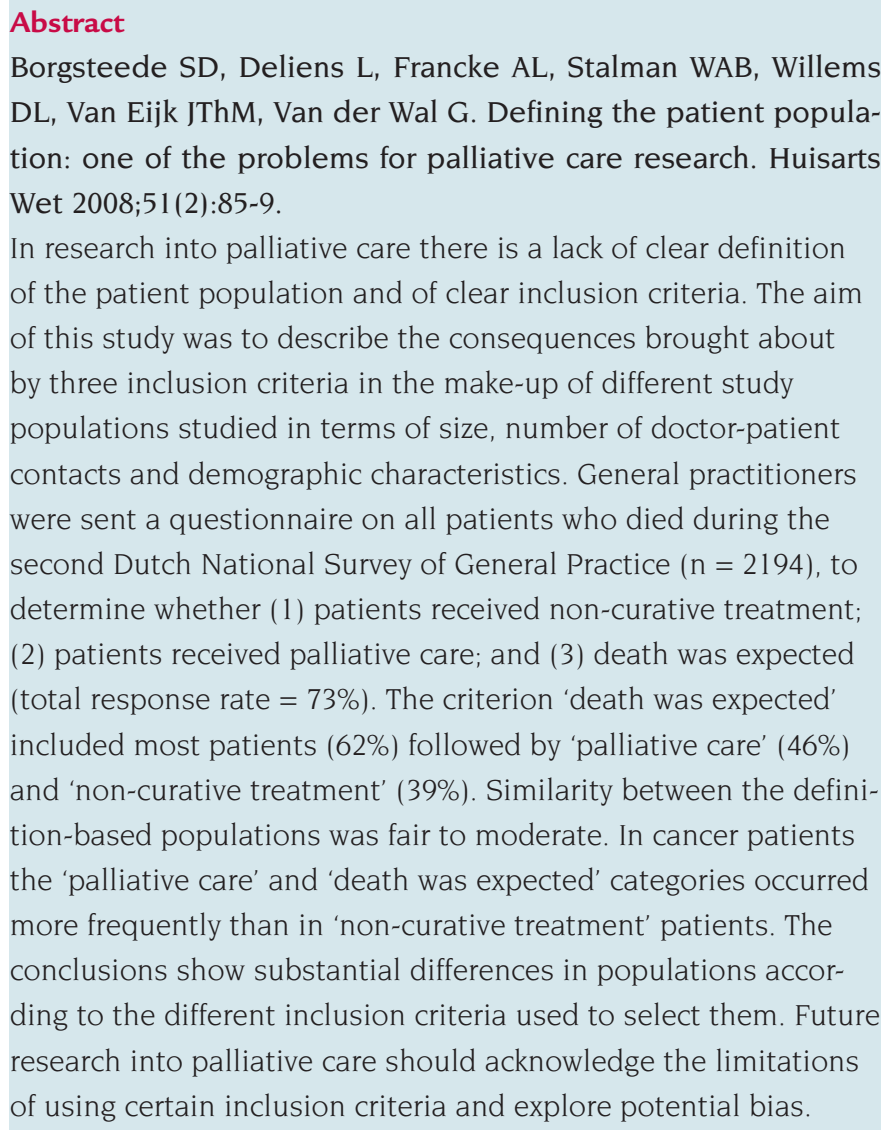

deze zorg verleende. Dit criterium kan men koppelen aan de ernst van de problemen en de frequentie van de huisarts-patiëntcontacten. Het derde criterium, 'overlijden werd verwacht', kan de kans weergeven dat het overlijden van de patiënt op korte termijn in de lijn der verwachting ligt. De drie criteria zijn niet onderling verwisselbaar en geven geen populaties zonder overlap. Het blijkt mogelijk dat een patiënt tegelijkertijd palliatieve zorg en een nietcuratieve behandeling kreeg, terwijl het overlijden niet op korte termijn werd verwacht.

Ook bestaat de kans dat het indelen van patiënten de zorg voor de patiënt beïnvloedt. In een onderzoek onder patiënten met darmen longkanker bleken patiënten van wie de huisarts de behandeling als palliatief omschreef, eerder te overlijden dan patiënten bij wie de huisarts de zorg anders noemde. ${ }^{14}$ Mogelijk verbonden artsen het label 'palliatieve zorg' vooral aan de ernstigere ziekten.

Ons onderzoek toont aan dat de populatie patiënten met 'palliatieve zorg' meer huisarts-patiëntcontacten had dan patiënten die onder een ander criterium vielen. De meeste van deze patiënten hadden kanker. Dit onderschrijft het argument dat palliatieve zorg gekoppeld is aan intensievere zorg. De vraag is echter of patiënten 'palliatieve zorg' kregen omdat ze kanker hadden, of omdat ze die intensievere zorg nodig hadden? Als de eerste veronderstelling juist is, bestaat de kans dat bepaalde chronisch zieke patiënten van wie het overlijden werd verwacht maar die geen 'palliatieve zorg' kregen, uitgesloten waren van de intensievere zorg die zij wel nodig hadden.

Om verschillen te beschrijven tussen subpopulaties met inbegrip van alle mogelijke patiënten die palliatieve zorg krijgen, moeten de criteria zo breed mogelijk zijn. Daarom adviseren wij om combinaties van criteria te gebruiken, met in ieder geval 'palliatieve zorg' als zodanig benoemd door professionele zorgaanbieders en de intentie van de zorg, namelijk niet gericht op genezing of levensverlenging. Daarnaast komt een inschatting van de levensverwachting van de patiënt. Dit is niet bedoeld als een voorspelling, want dat is moeilijk, ${ }^{15}$ maar als een aanwijzing voor een mogelijk traject van palliatieve zorg.

Om de kennis over palliatieve zorg te verbeteren, zouden we een internationaal aanvaarde combinatie van criteria moeten vinden waarmee we de palliatieve zorg kunnen vergelijken onder verschil- 
lende omstandigheden, tussen landen en tussen subpopulaties. Hiermee kan de ontwikkeling van een internationaal aanvaarde definitie van onderzoek op gang komen, iets wat essentieel is voor de verdere ontwikkeling van onderzoek naar palliatieve zorg.

\section{Literatuur}

1 WHO. Cancer Pain Relief and Palliative Care. Technical Report Series 804. Geneva: World Health Organization, 1990.

2 WHO. National cancer control programmes: policies and managerial guidelines. Geneva: World Health Organization, 2002

3 Lynn J, Harrell FE, Cohn F, Hamel M, Dawson N, Wu AW. Defining the "terminally ill": insights from SUPPORT. Duquesne Law Rev 1996;35:311-36

4 George LK. Research design in end-of-life research: state of science Gerontologist 2002;42 Spec No 3:86-98.

5 Lorenz K, Lynn J, Morton CS, Dy S, Mularski R, Shugarman L, et al. Appendix A. Scope of End-of-Life Populations. End-of-Life Care and Outcomes, p A1-A13. Rockville, MD, USA: Agency for Healthcare Research and Quality, 2004.

6 Teno JM, Coppola KM. For every numerator, you need a denominator: a simple statement but key to measuring the quality of care of the “dying". J Pain Symptom Manage 1999;17:109-13.

7 Onwuteaka-Philipsen BD, Van der Heide A, Koper D, Keij-Deerenberg I, Rietjens JA, Rurup ML, et al. Euthanasia and other end-of- life decisions in the Netherlands in 1990, 1995, and 2001. Lancet 2003;362:395-9

8 Van der Heide A, Deliens L, Faisst K, Nilstun T, Norup M, Paci E, et al. End-of-life decision-making in six European countries: descriptive study. Lancet 2003;362:345-50

9 Westert GP, Schellevis FG, De Bakker DH, Groenewegen PP, Bensing JM, Van der Zee J. Monitoring health inequalities through general practice: the Second Dutch National Survey of General Practice. Eur J Public Health 2005; 15:59-65

10 Lamberts $\mathrm{H}$, Woods M, Hofmans-Okkes I. The international classification of primary care in the European Community. Oxford: Oxford University Press, 1993.

11 Altman DG. Practical statistics for medical research. London: Chapman \& Hall, 1991

12 Sibbald B, Addington-Hall J, Brenneman D, Freeling P. Telephone versus postal surveys of general practitioners: methodological considerations. Br J Gen Pract 1994;44:297-300.

13 Walsh D, Regan J. Terminal care in the home--the general practice perspective. Ir Med J 2001;94:9-11

14 Farquhar M, Grande G, Todd C, Barclay S. Defining patients as palliative: hospital doctors' versus general practitioners' perceptions. Palliat Med 2002;16:247-50.

15 Christakis NA, Lamont EB. Extent and determinants of error in doctors' prognoses in terminally ill patients: prospective cohort study. BMJ 2000;320:469-72.

\section{EVIBAS}

(evidencebasalastine)

In geneesmiddelenreclames wordt vaak de term 'evidence based' gebruikt. Per definitie is een geneesmiddel niet 'evidence based', alleen een behandeling bij een bepaalde patiënt kan dat zijn.

'Evidence-based' medicine is het expliciet en afgewogen toepassen van de resultaten van goed medisch-wetenschappelijk onderzoek in de klinische praktijk. Het praktiseren van 'evidence-based' medicine houdt een integratie in van kennis uit onderzoek (evidence) met praktische ervaring van de arts om zo tot optimale zorg voor de patiënt te komen.

\section{(1)}

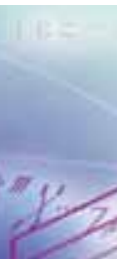

(1)

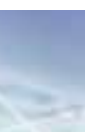

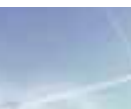

